\title{
THE PARTIAL PURIFICATION AND PROPERTIES OF ANTIBIOTIC SUBSTANCES FROM THE BANANA (MUSA SAPIENTUM) ${ }^{1,2}$
}

\author{
By WILLIAM E. SCOTT, HAZEL H. MCKAY, P. S. SCHAFFER, \\ AND THOMAS D. FONTAINE \\ (From the Bureau of Agricultural and Industrial Chemistry, Agricultural Research Center, \\ Beltsville, Maryland)
}

Recent investigations have shown that extracts of higher plants contain substances which inhibit the growth of bacteria and fungi (1). In a preliminary survey conducted by this laboratory, approximately $40 \%$ of the extracts from the 80 plants tested exhibited either antibacterial or antifungal activity or both. Among the plants tested was the banana. Bananas have been used clinically for dietary purposes and for some intestinal disorders (2), but their beneficial effect has never been attributed to the presence of antibiotic substances. The banana skin has been referred to as nature's bacteria-proof wrapper and investigations have shown that when bananas were immersed in fluids containing cultures of known organisms there was no evidence of a penetration into the interior (3).

The purpose of this paper is to present the partial antibiotic spectrum of extracts obtained from the pulp and skins of green, naturally ripened, and ethylene-ripened bananas, and from banana leaves and petioles, and to describe the partial purification of these antibiotic substances.

\section{EXPERIMENTAL}

\section{Preparation of extracts}

Fresh undried plant material was extracted with water. Plant material previously dried at $85^{\circ} \mathrm{C}$ in a forced-draft oven and ground to pass a medium Wiley mill screen was extracted with methanol or petroleum ether (b.p. $\left.35-60^{\circ} \mathrm{C}\right)$. Aqueous, methanol, and petroleum-ether extracts were concentrated until each milliliter of solution was equivalent to $1 \mathrm{gm}$. of the plant material. In some experiments the organic-solvent extracts were evaporated to dryness and sufficient water to make each milliliter of solution equivalent to $1 \mathrm{gm}$. of original plant material was then added to the residues. Frequently, not all of the substance dissolved by organic solvent was

1 Presented at the Second National Symposium on Recent Advances in Antibiotics Research held in Washington, D. C., April 11-12, 1949, under the auspices of the Antibiotics Study Section, National Institutes of Health, Public Health Service, Federal Security Agency.

${ }^{2}$. Report of a study made under the Research and Marketing Act of 1946. soluble in water. In these cases the water-soluble portion was removed, and the water-insoluble portion was tested separately. The $\mathrm{pH}$ of all aqueous solutions was determined and then adjusted to $6-7$ for assay, although no appreciable difference in the size of inhibition zones was noted when the aqueous solutions were not adjusted from their normal $\mathrm{pH}$ of 4.0 to 5.5 .

\section{Method of assay}

Sterile, $90 \mathrm{~mm}$. petri dishes, containing $20 \mathrm{ml}$. of solidified agar media, were warmed to $45^{\circ} \mathrm{C}$ and flooded with $4 \mathrm{ml}$. of agar, seeded with bacterial cells or fungus spores. In the cylinder cup-plate method the plant extracts were pipetted into the cups which had been placed on the inoculated agar, and in the paper disc method the discs were immersed in the plant extract long enough to become saturated with the solution and then dried in a vacuum desiccator. Before they were placed on the inoculated agar the discs were moistened with distilled water. The agar plate was incubated for a fixed period of time at a temperature that was optimum for the growth of the organism. The zones of inhibition around the cups or discs were measured to obtain a relative indication of the amount of antibiotic agent in the extract. See (1) for source of organisms.

\section{Antibiotic activity of crude extracts}

Aqueous extracts of banana leaves and petioles showed no detectable antibiotic activity. The water-soluble portion of the substance extracted by methanol exhibited no appreciable antifungal activity, whereas the water-insoluble portion inhibited the growth of the fungus Fusarium oxysporum f. lycopersici.

Some antibacterial activity was detected in the methanol extracts of both plant parts. The water-soluble portion of the substance extracted from leaves by methanol inhibited Xanthomonas translucens f. sp. hordei-avenae and Rhodococcus roseus and partially inhibited Sarcina lutea and Serratia marcescens, whereas the same portion from the methanol extract of petioles inhibited Staphylococcus aureus, $S$. lutea, Mycobacterium phlei, and $R$. roseus.

A comparison of the antifungal and antibacterial activities of the water-soluble substance in methanol extracts of the pulp and skins of green, naturally ripened, and ethylene ripened bananas ${ }^{8}$ is shown by Table $\mathrm{I}$.

3 The green, naturally ripened and ethylene ripened bananas were obtained from the Bureau of Plant Industry, Soils, and Agricultural Engineering, Beltsville, Maryland. 
TABLE I

-Comparison of the activities* of extracts obtained from the pulp and skins of green, naturally ripened, and ethylene-ripened bananas

\begin{tabular}{|c|c|c|c|c|c|c|}
\hline \multirow{2}{*}{ Organiamt } & \multicolumn{3}{|c|}{ Skins } & \multicolumn{3}{|c|}{ Pulp } \\
\hline & Green & $\begin{array}{c}\text { Naturally } \\
\text { ripened }\end{array}$ & $\begin{array}{l}\text { Ethylene- } \\
\text { ripened }\end{array}$ & Green & $\begin{array}{l}\text { Naturally } \\
\text { ripened }\end{array}$ & $\begin{array}{l}\text { Ethylene- } \\
\text { ripened }\end{array}$ \\
\hline $\begin{array}{l}\text { Fusarium oxysporum f. } \\
\text { lycopersici }\end{array}$ & $29+$ & $25+$ & $29+$ & $17-, 25+$ & $28+$ & $32.5+$ \\
\hline Escherichia coli & $27(-)$ & $25+, 28-$ & $22+, 28-$ & $23(-)$ & $25+, 33-$ & $28+, 34-$ \\
\hline Slaphylococcus aureus & $18(+), 23(-)$ & $25+, 28(-)$ & $19+, 25(+)$ & $20(+)$ & $27+, 32-$ & $27+, 35-$ \\
\hline Serratia marcescens & $26(+), 33(-)$ & $27+, 34-$ & $32+, 37-$ & $24(+), 33(-)$ & $28+, 35-$ & $30+, 37-$ \\
\hline Mycobacterium phlei & $18(-)$ & + & $19+$ & 0 & + & $18+$ \\
\hline Bacillus subtilis & & & $\begin{array}{l}19+,-1 \\
33(+),(-)\end{array}$ & & & $\begin{array}{l}17+,- \\
39(+), 42(-)\end{array}$ \\
\hline Sarcina lutea & & & $29+$ & & & $25+$ \\
\hline Rhodococcus roseus & & & $28+,(-)$ & & & $23+$ \\
\hline $\begin{array}{l}X \text { anthomonas translucens } \\
\text { f. sp. hordei-avenae }\end{array}$ & & & $30+$ & & & $24+$ \\
\hline
\end{tabular}

- The numbers refer to the diameter of the zone in millimeters; for instance, $25+, 28-$ means an inhibition zone of $25 \mathrm{~mm}$. and a stimulation zone of $3 \mathrm{~mm}$. beyond the $25 \mathrm{~mm}$. zone. +, inhibition; $(+)$, partial inhibition; -, stimulation; (-), partial stimulation; $0=$ no effect.

t See previous paper (1) for source of organisms.

\section{RESULTS}

Antifungal activity was exhibited by all six extracts. There was very little, if any, measurable antibacterial activity in either the pulp or skins of green bananas, but there was appreciable antibacterial activity in the pulp and skins of ripe bananas. In some instances the inhibition zones were surrounded by zones of stimulation. This may be due either to the carbohydrates which are present, mainly as sugars, in ripe bananas (4) or to a subminimal amount of antibiotic at the outer edge of the zone of inhibition or to a combination of both factors. The partial inhibition zones resulting from extracts of the pulp and skins of green bananas may be explained by the fact that some of the bananas were partly ripe. It appears that the antibacterial activity of bananas is due to the formation of inhibitory compounds during ripening. Petroleum ether did not extract any of the active substance from either the pulp or the skins.

Agar slants of the water-soluble portion of a crude methanol extract of the skins indicate that the substance at a concentration of $0.25 \mathrm{gm}$. of dried plant material per $\mathrm{ml}$. of medium is fungistatic to $F$. oxysporum f. lycopersici, Trichophyton mentagrophytes, Monosporium apiospermum and Blastomyces dermatitidis.

\section{Fractionation and partial purification}

Dried skins (1,325 gm.) from ethylene-ripened and naturally ripened bananas were combined and extracted, batchwise, with 10 successive $1,500-\mathrm{ml}$. portions of hot methanol, and the combined extracts were subsequently concentrated to approximately 2 liters. When this concentrate was cooled to $-20^{\circ} \mathrm{C}$, some resinous material was precipitated. The supernatant methanolic solution was filtered and concentrated under reduced pressure to approximately $1,300 \mathrm{ml}$. so that each $\mathrm{ml}$. of solution represented about $1.0 \mathrm{gm}$. of dried skins. This solution showed a notable increase in antifungal activity, producing an inhibition zone of 62 $\mathrm{mm}$. against $F$. oxysporum f. lycopersici, which is more than twice the diameter of the zone produced by solutions from which the resinous material had not been separated, but it did not show any appreciable change in antibacterial activity. As- 
says of ethanol solutions of the resinous material showed slight inhibitory activity toward bacteria and some stimulatory activity toward $F$. oxysporum f. lycopersici.

Thus far, chromatographic adsorption of the antibiotic substances in methanol extracts, and in the petroleum-ether-soluble portion of methanol extracts, by activated alumina has not proved very satisfactory. Activated carbon (Darco G-60) did not adsorb the antibiotic substances from an aqueous extract ( $\mathrm{pH}$ 5.0) of the methanol concentrate.

Low pressure distillation of a methanol concentrate of ripe banana skins produced a small amount of liquid from which a few crystals have been obtained. During the distillation, at 2-mm. pressure, the tendency to foam was controlled by cautious heating. A few drops of distillate were collected at a pot temperature of $180-190^{\circ} \mathrm{C}$, and a few additional drops as the pot temperature rose to $250^{\circ} \mathrm{C}$. Both distillates were readily soluble in ethanol, but upon the addition of a few drops of water the solutions became turbid. Crystals formed in each solution when cooled in the refrigerator for a few days. At the time of writing, the crystals had not been tested for antibiotic activity, but the original solution from which the crystals separated had been found to exhibit both antifungal and antibacterial activity (Table II). The physical and chemical properties of the crystalline substance have not yet been determined.

TABLE II

\section{Activity of the distillate obtained from ripe banana skins}

Organism*

Fusarium oxysporum f. lycopersici

Escherichia coli

Staphylococcus aureus

Sarcina lutea

Xanthomonas translucens $\mathrm{f} . \mathrm{sp}$.

hordei-avenae

Mycobacterium phlei

Bacillus cereus

* See previous paper (1) for source of organisms.

\section{DISCUSSION}

The results show that all four parts of the banana plant tested contain some extractable antibiotic

4 The mention of this and other commercial products does not imply that they are endorsed or recommended by the Department of Agriculture over others of a similar nature not mentioned. agent(s). Since the pulp and skins of both green and ripe bananas showed antifungal activity, and the pulp and skins of only ripe bananas showed antibacterial activity, it seems likely that there are at least two separate antibiotic agents in ripe bananas. Further, the antibacterial substance appears to be a product formed during the ripening process. It is interesting to note that a vacuumdistillable substance was obtained from ripe banana skins which had both antifungal and antibacterial activity.

Adsorption on alumina and on activated charcoal produced no positive results, but these procedures have not yet been fully investigated.

The in vitro antifungal and antibacterial activity of the various parts of the banana plant warrants further investigation to isolate, identify and characterize the active substance or substances. Because of the in vitro effectiveness of these principles, toxicological investigations are now in progress.

\section{SUMMARY}

1. Extracts of banana leaves were found to be only slightly antibacterial, whereas extracts of stems inhibited the growth of two Gram-positive, one acid-fast Gram-positive, and one Gram-variable bacterium.

2. Extracts of the pulp and skins of green bananas inhibited only the fungus $F$. oxysporum $f$. lycopersici.

3. Extracts of the pulp and skins of ripe bananas effectively inhibited $F$. oxysporum f. lycopersici, Escherichia coli, Staph. aureus, S. marcescens, $M$. phlei, Bacillus subtilis, $S$. lutea, $R$. roseus, and $X$. translucens f. sp. hordei-avenae.

4. A substance distillable at low pressure effectively inhibits $F$. oxysporum f. lycopersici, $E$. coli, Staph. aureus, S. lutea, M. phlei, Bacillus cereus, and $X$. translucens $\mathrm{f}$. sp. hordei-avenae.

5. The results indicate that the banana plant contains one or more substances with therapeutic possibilities provided their toxicity and in vivo activity are favorable.

\section{ACKNOWLEDGMENT}

The assistance of Mrs. Barbara Black in conducting antibiotic assays, and of Mr. Francis Guay for the preparation of some banana extracts, is greatlv appreciated. 


\section{BIBLIOGRAPHY}

1. Bruckner, B. H., McKay, H. H., Schaffer, P. S., and Fontaine, T. D., The partial purification and properties of antibiotic substances from the sweet potato plant (Ipomoea batatas). J. Clin. Invest., 1949, 28, 894. (See the eight references under "Bibliography.")
2. Bogert, L. J., Dietary uses of the banana in health and disease. A review of scientific literature. United Fruit Company, New York, 1942.

3. Kar, N. R., Chemical composition and nutritive value of bananas. Science \& Culture, 1938, 4, 76.

4. Barnell, H. R., Studies in tropical fruits. XI. Carbohydrate metabolism of the banana during ripening under tropical conditions. Ann. Bot., 1941, 5, 217. 